\title{
Creep compliance of asphalt binders by indentation
}

\section{Flexibilidad en fluencia de ligantes asfálticos mediante indentación}

Rodrigo Delgadillo (Main and Corresponding Author)

Departamento de Obras Civiles, Universidad Técnica Federico Santa María

Av. España 1680, Valparaíso (Chile)

rodrigo.delgadillo@usm.cl

\section{Angelo Filonzi}

Departamento de Obras Civiles, Universidad Técnica Federico Santa María

Av. España 1680, Valparaíso (Chile)

filonzi@utexas.edu

\section{Hussain Bahia}

Civil \& Environmental Engineering Department, The University of Wisconsin

Environmental Engineering, 1415 Engineering Dr., WI 53706, Madison (USA)

bahia@engr.wisc.edu

\section{Nima Roohi Sefidmazgi}

Civil \& Environmental Engineering Department, The University of Wisconsin Environmental Engineering, 1415 Engineering Dr., WI 53706, Madison (USA) roohisefidma@wisc.edu

Manuscript Code: 815

Date of Acceptance/Reception: 09.03.2018/22.09.2016

DOI: 10.7764/RDLC.17.1.85

\begin{abstract}
A solution for measuring creep compliance of asphalt binders is obtained by testing samples using a spherical indenter at intermediate temperatures. The initial assumptions considered a semi-infinite medium with no friction. Solutions were obtained to correct for the finite height and radius of the samples. Three non-modified asphalt binders were tested at intermediate temperatures $\left(20-25^{\circ} \mathrm{C}\right)$ using three load levels $(25-50-75 \mathrm{~g})$. Three sample radius $(25-35-50 \mathrm{~mm})$ and three sample heights $(15-30-50 \mathrm{~mm})$ were considered, thus obtaining a total of nine sample sizes. The binders were also tested in creep using a dynamic shear rheometer and results were compared with indentation. For the three asphalt binders analyzed, creep compliances obtained by indentation turned to be lower than the values measured using dynamic shear rheometers. One probable reason for this difference is the excessive aging that is induced on the surface of samples to be indented during sample preparation, as well as the effects of friction and indentation depth during testing. Future studies should consider the effect of friction in the indentation, which seem not to be totally negligible.
\end{abstract}

Key words: Spherical indenter, indentation test, asphalt binder, viscoelasticity, creep compliance, rheology.

\section{Resumen}

Se obtiene una solución para medir la deformación en fluencia de los ligantes asfálticos al analizar muestras utilizando un indentador esférico a temperaturas intermedias. Las suposiciones iniciales consideran un medio semi-infinito sin fricción. Se obtuvieron factores para corregir la altura y radio finito de las muestras y se analizaron tres ligantes asfálticos no modificados a temperaturas intermedias ( $\left.20-25{ }^{\circ} \mathrm{C}\right)$ utilizando tres niveles de carga (25 - 50 - 75 g). Se consideraron tres radios de muestra (25 - 35 - 50 mm) y tres alturas (15 - 30 - 50 mm), obteniendo nueve tamaños de muestra. Los ligantes asfálticos también se ensayaron en fluencia utilizando un reómetro de corte dinámico y los resultados se compararon con la indentación. Para los tres ligantes asfálticos analizados, las flexibilidades en fluencia obtenidas por indentación resultaron ser menores que los valores medidos utilizando reómetros de corte dinámico. Probablemente esta diferencia se debe al envejecimiento provocado en la superficie de las muestras durante su preparación, así como los efectos de la fricción y la profundidad de la indentación durante el ensayo. Los estudios futuros deberían considerar el efecto de la fricción en la indentación, la cual, no parece ser totalmente despreciable.

Palabras clave: Indentador esférico, ensayo de indentación, ligante asfáltico, viscoelasticidad, flexibilidad en fluencia, reología.

\section{Introduction}

Asphalt pavements are materials that contain mineral aggregates, asphalt binder and air voids. Appropriate material characterization is required for aggregates and binder, while the proper void content needs to be provided to the asphalt mixtures (Marin \& Thenoux, 2014). Asphalt binders are viscoelastic materials and their response to loading depends on 
load time and temperature (Read \& Whiteoak, 2003). Adequate characterizations for viscoelastic materials require determining their fundamental viscoelastic functions. In the time domain, these correspond to the creep compliance and relaxation modulus. In the frequency domain, fundamental characteristics are the complex modulus and phase angle of the material.

The viscoelastic properties at different loading times and temperatures have a great influence in pavement performance (Hajj, Souliman, Alavi \& Loría Salazar, 2013). The response at high temperatures and long loading times is directly correlated to permanent deformation of pavements, known as rutting. The low temperatures characteristics determine the thermal cracking susceptibility while the intermediate temperature properties are related to fatigue cracking of pavements (García, Bueno, Norambuena-Contreras \& Partl, 2013; Valdés Vidal, Miró Recasens \& Martínez Reguero, 2015).

In many places like in South America and Europe, asphalt binders are characterized in a simple way by using empirical parameters that only allows comparison among materials but not providing information related to the fundamental material properties (MOP, 2003). Several testing procedures like penetration (ASTM D5), softening point (ASTM D36), ductility (ASTM D113), and Fraass breaking point (EN 12593) allow for the comparison of materials under certain conditions, but do not provide information about the viscoelastic characteristics of material. These procedures are still being used, due to its low cost and ease of implementation.

The Penetration test (ASTM D5) is performed by using a penetrometer. This equipment has a needle as an indenter. The results allow for the comparison between the asphalt binders consistency and it is generally measured at $25^{\circ} \mathrm{C}$. This is an equipment of relatively low cost, but there is no analytical solution for the indentation geometry used. To obtain the creep compliance it is required to use an indenter tip geometry having a known solution, such as the spherical tip (Yang \& Li, 2008).

In the United States and Canada, asphalt binders are characterized using rheometers (AASHTO MP19). The Bending Beam Rheometer BBR (AASHTO T313) is used at low temperatures. The Dynamic Shear Rheometer DSR (AASHTO T315) is used at intermediate and high temperatures (Roberts, Kandhal, Brown, Lee \& Kennedy, 1991). The DSR allows for complete and advanced characterization of the asphalt binder materials. Nonetheless, this equipment and its implementation increase the cost.

Proper asphalt binder characterization by means of reasonably affordable equipment is a very important need, and sets an interesting challenge for asphalt engineers. The study of indentation as alternative for the evaluation of binders has already been discussed (Anderson et al., 1994; WRI, 2010). Some studies (Ossa, Deshpande \& Cebon, 2005) have characterized the binder using a monotonic and cyclic loading in indentation tests. Also, Zofka \& Nener-Plante (2011) presented a solution for the creep compliance in tension using a flat cylindrical indenter. The present research evaluates the possibility of using a modified penetrometer to obtain asphalt binder's viscoelastic functions at intermediate temperatures.

Indenter modelling

Aspects to be considered for contact mechanics include pressure and adhesion in the normal direction (perpendicular to the surfaces of both bodies) and frictional stresses. Initial studies on contact mechanics date back to Hertz (1882), who studied and solved the case of two curved surfaces in contact for the elastic case. That solution for the problem of non-adhesive elastic contact is still valid and provides the base for the modern problems in contact mechanics between diverse axially symmetric indenter tip geometries (Sneddon, 1965).

Further studies (Johnson, Kendall, \& Roberts, 1971) incorporated the effect of adhesion between bodies in the model known as JKR (after Johnson, Kendall and Roberts). Adhesion generates an increase in the real contact area between bodies, compared to the Hertzian solution of non-adhesive elastic contact. Bowden \& Tabor (2001) were the first to emphasize the importance of surface roughness for bodies in contact. These authors showed that when this effect is included, it generates a decrease in the area of real contact between bodies.

Material characterization using indentation test has the advantage of requiring relatively simple procedures. The analysis required by models incorporating friction or adhesion, however, it can be complex, requiring additional materials' information, like their surface energy. In this exploratory research, results assuming frictionless contact using a spherical indenter tip are analyzed. The same assumption was made in the research developed by Ossa et al. (2005) and Zofka \& Nener-Plante (2011). Hertz theory assumptions are as follows:

- The surfaces are continuous and non-conforming. 
- The strains are small and within the elastic limit.

- Each body can be considered as elastic half space, i.e., the area of contact is much smaller than the characteristic radius of the bodies.

- The contact surfaces are frictionless.

Viscoelastic materials' characterization is more challenging as their behavior is time-dependent. Most of the viscoelastic indentation solutions apply the functional equations method developed for the linear viscoelastic problem by Lee \& Radok (1960). This method allows time dependent boundary conditions, unlike the Laplace transform conditions, whose original approach was developed by Lee (1955). A hereditary integral operator is applied in the Lee and Radok method to find tensions as a function of time and deformations based on Hertz elastic solution. For practical purposes of indentation, solutions obtained by using the method of functional equations are valid only if contact area between the indenter tip and the material surface is increasing in time (Hunter, 1960).

\section{Spherical indenter modelling}

Lee \& Radok (1960) obtained a solution for rigid spherical indenter on an isotropic linear viscoelastic media assuming surfaces in contact are frictionless. Friction can be neglected if indentations $h(t)$ are smaller than $20 \%$ of the indenter radius (Sharpe, 2008; Cao \& Lu, 2004). The solution is presented in Equation 1. The schematic of the indentation is presented in Figure 1.

$$
J(t)=\frac{8 \sqrt{R}}{3 P_{0}(1-v)} h(t)^{3 / 2}
$$

Where:

$P_{0}: \quad$ applied constant load

$R: \quad$ radius of the spherical indenter

$J(t)$ : creep compliance in shear of the indented media (asphalt binder)

$v: \quad$ Poisson's ratio of the indented media (asphalt binder)

$a: \quad$ contact radius

$h(t)$ : indentation depth (measured from the original surface level)

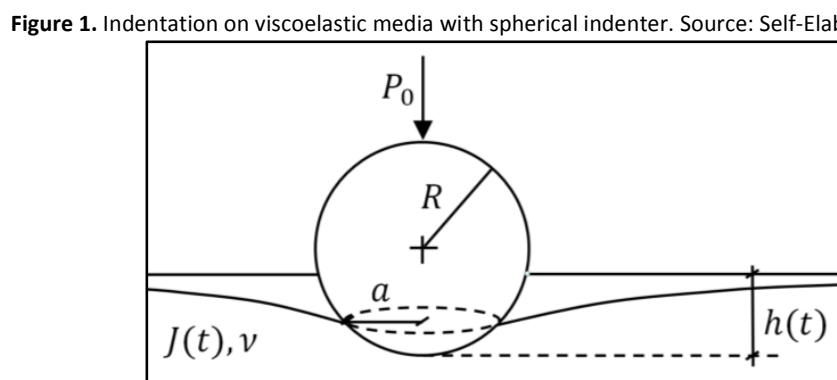

\section{Effect of the finite sample size}

The solution presented above assumes a semi-infinite medium to be indented. Nonetheless, sizes of the real samples do not necessarily allow this assumption to be valid. Moreover, from a practical point of view, smaller size samples are easier to be handled and have lower costs. Therefore, determining the influence of the finite sized samples' boundary condition on the indentation results is of interest. Boundary conditions on the surface of the semi-infinite material to be indented are:

$$
\begin{array}{ll}
w(r, 0)=\delta & r=0 \\
\sigma_{z z}(r, 0)=0 & r>a \\
\sigma_{r z}(r, 0)=0 & r \geq 0
\end{array}
$$

Where $w$ is the vertical displacement field, $\sigma_{z z}$ is the normal stress component and $\sigma_{r z}$ is the tangential stress component. If the sample has a finite depth (assuming infinite horizontal dimensions) and the base of the sample is considered to be limited by an infinitely rigid material, additional boundary conditions apply. At the sample base $H_{s}$, in the interphase between the material to be indented and the rigid container, boundary conditions are as follows: 


$$
u\left(r, H_{s}\right)=w\left(r, H_{s}\right)=0 \quad r \geq 0
$$

Where $u$ is the horizontal displacement field. The solution can be mathematically reduced to a second type of Fredholm integral equation (Li \& Vlassak, 2009; Han, Saha \& Nix, 2006).

When the sample has infinite depth, but finite horizontal dimensions, lateral boundary conditions need to be satisfied. Complete adhesion can be assumed between the asphalt bitumen sample and the rigid container. Thus, lateral boundary conditions at the surface are:

$$
u\left(R_{s}, 0\right)=w\left(R_{s}, 0\right)=0
$$

Where $R_{S}$ is the radius of the cylindrical container. These boundary conditions can be imposed on the surface vertical displacement using load superposition.

Correction factors CF can be obtained and expressed as a ratio between the indentation in a semi-infinite media and the indentation in a confined media. Figure 2 shows the correction factors for sample of finite lateral dimensions and finite depth. The detailed procedure for obtaining the corrections is not presented here due to space limitations and the mathematical derivation can be reviewed in previous works (Filonzi, 2013; Filonzi \& Delgadillo, 2017). The correction factors are expressed in terms of a normalized parameters $H_{s} / a$ or $R_{s} / a$ for base or lateral corrections, respectively. $H_{s}$ refers to the depth of the sample and $R_{S}$ is the radius of the cylindrical sample and $a$ is the contact radius previously defined.

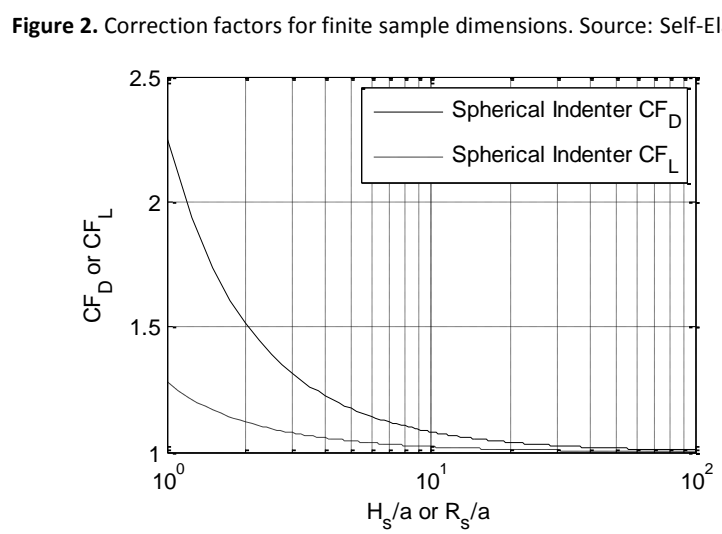

Experimental work

\section{Testing conditions}

Cylindrical containers have been used because of their axial symmetry advantage. Nine tube sizes were selected, combining three different radii and heights. Steel containers have been used because of their high relative rigidity as compared to asphalt binder. This material allows the assumption of no deformation in containers during testing. Test tubes, indenter dimensions and testing conditions are shown in Table 1.

\begin{tabular}{lc}
\multicolumn{2}{l}{ Table 1. Testing conditions and sample' sizes. Source: Self-Elaboration. } \\
\hline Parameter & Value \\
\hline Indenter radius $[\mathrm{mm}]$ & 8.5 \\
Indentation load $[\mathrm{g}]$ & $25-50-75$ \\
Test tube radius $[\mathrm{mm}]$ & $25-35-50$ \\
Test tube height $[\mathrm{mm}]$ & $15-30-50$ \\
Testing time $[\mathrm{s}]$ & 40 \\
Testing temperature $\left[{ }^{\circ} \mathrm{C}\right]$ & $20-25$ \\
\hline
\end{tabular}

The creep compliance function in shear $J(t)$, obtained from indentation testing, depends on the Poisson's ratio of the material to be indented. Therefore, an adequate value of the Poisson's ratio should be used for the asphalt binder considering the testing conditions. 
Asphalt binders are traditionally considered as non-compressible. Recent researches (Benedetto, Delaporte \& Sauzéat, 2007) have determined that Poisson's ratio value varies with the temperature of asphalt binder. Specifically, in the case of low temperatures, such non-compressibility assumption seems not to be accurate. Nevertheless, based on the findings by Benedetto et al. (2007) the Poisson's ratio assumption of 0.5 is valid under the testing conditions considered in this paper $\left(20-25^{\circ} \mathrm{C}\right)$. This value could be questionable only for extremely short load intervals; hence, special consideration must be taken to interpret creep functions for short times.

\section{Sample preparation and testing equipment}

Asphalt binder samples are poured while hot inside the cylindrical containers. The temperature used to liquefy them was $163^{\circ} \mathrm{C}$ and the time considered was the minimum required to ensure that the sample is fluid, to avoid excessive aging. After pouring, the samples are heated for one hour in a conventional oven at $163{ }^{\circ} \mathrm{C}$. This additional heating is necessary to generate an entirely flat surface and to allow the expulsion of air bubbles formed in the material while pouring it into the containers. Finally, the samples are conditioned at the testing temperature in a temperature controlled room for several hours until temperature is stable. Figure 3(a) displays a set of samples ready to be tested.

The equipment for indentation testing was a modified penetrometer (WRI, 2010; Bahia, Meruva \& Velasquez, 2011). The indenter's vertical displacement (indentation depth $h$ ) is recorded by an automatic data acquisition system at one second intervals to improve the resolution of measurements compared to a traditional penetrometer. A counterweight system was added to ensure the accuracy of the indentation load. The timing between the beginning of the test and the start of the recording is achieved manually. Figure $3(\mathrm{~b})$ shows an image of the testing device.

The three binders tested were labeled L1 (PG64-22), L2 (PG64-16) and L3 (PG64-16 reheated). Binders L1 and L2 were subjected to the same procedure described in the paragraph above. Binder L3 is the same as binder L2, which was subjected to a second heating cycle. In other words, after testing the L2 samples, these samples were again placed for one hour in the oven at $163^{\circ} \mathrm{C}$. This allowed for the surface of the samples to flatten again and be ready for another test. This reheated binder was labeled $\mathrm{L} 3$.

Since one of the objectives of this research is binder characterization with low-cost equipment, no specialized temperature control devices have been considered. The use of under water temperature control has also been disregarded, because this procedure makes it difficult to position the indenter exactly on the surface before starting the test. With the penetrometer, the indenter has to be placed manually on the surface. The proximity of the surface is confirmed visually. The water bath does not allow for a clear vision of the spherical indenter placed right on the surface. Additionally, to keep the water temperature constant through the test, there is a need of water circulation, which caused significant noise in measurement of indentation depth.

The temperature control was achieved in a temperature controlled room. The temperature variations measured during testing were considered in the analysis. The samples were conditioned all night in the temperature controlled room, to allow for temperature stability. While performing the tests, temperature was continuously monitored using two thermocouples and one thermometer. For asphalt binder L1 (PG64-22) the temperature range recorded was between 20.6 and $21.4^{\circ} \mathrm{C}$. Testing of binder L2 (PG64-16) recorded a temperature range between 23.1 and $23.5^{\circ} \mathrm{C}$. Finally, for binder L3 (PG64-16 reheated) the temperature range varied between 22.2 and $22.4^{\circ} \mathrm{C}$.

\section{Experimental matrix}

A total of 45 tests were carried out for different sample sizes and indentation loads. The results analysis included the effect of initial contact, repeatability, sample height, sample radius and the effect of load magnitude. The testing matrix is shown in Table 2. 


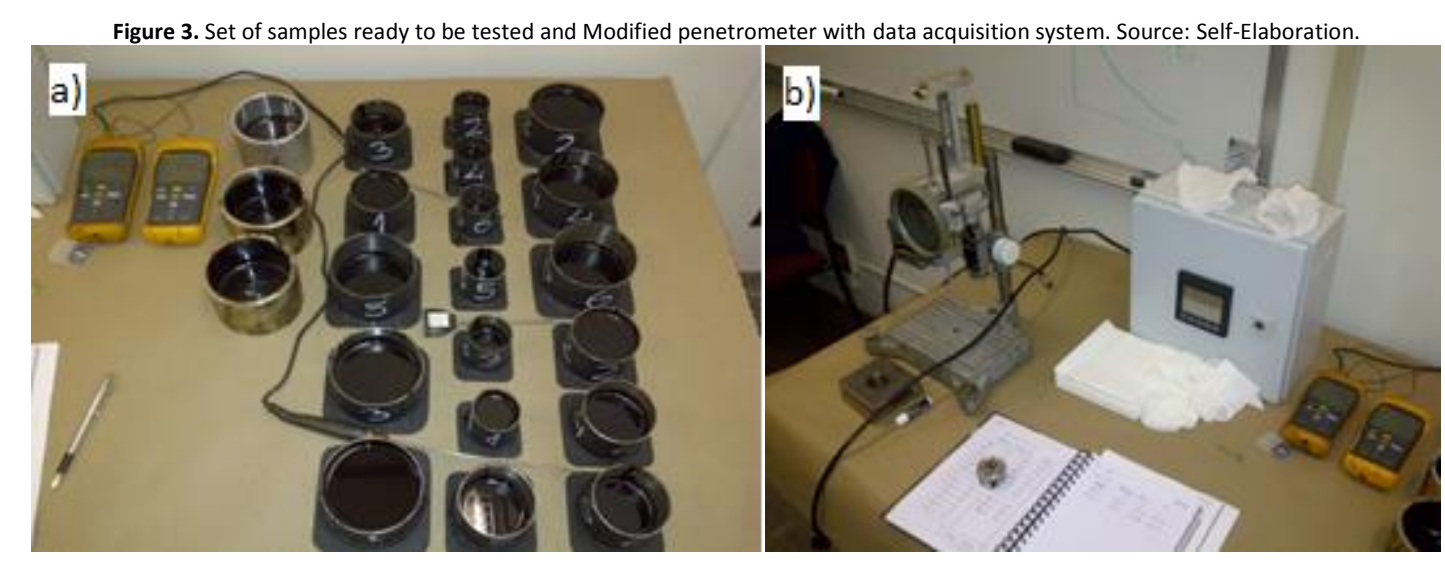

\begin{tabular}{|c|c|c|c|c|c|c|c|c|c|c|c|}
\hline \multicolumn{4}{|c|}{ L1 (PG64-22) } & \multicolumn{4}{|c|}{ L2 (PG64-16) } & \multicolumn{4}{|c|}{ L3 (PG64-16 reheated) } \\
\hline $\begin{array}{l}\text { Test } \\
\text { Tube } \\
\end{array}$ & $\begin{array}{c}\text { Diamete } \\
{[\mathrm{mm}]}\end{array}$ & $\begin{array}{c}\text { Height } \\
{[\mathrm{mm}]}\end{array}$ & $\begin{array}{l}\text { Load } \\
\text { [g] }\end{array}$ & $\begin{array}{l}\text { Test } \\
\text { Tube }\end{array}$ & $\begin{array}{c}\text { Diamete } \\
{[\mathrm{mm}]}\end{array}$ & $\begin{array}{c}\text { Height } \\
{[\mathrm{mm}]}\end{array}$ & $\begin{array}{c}\text { Load } \\
{[\mathrm{g}]}\end{array}$ & $\begin{array}{l}\text { Test } \\
\text { Tube }\end{array}$ & $\begin{array}{c}\text { Diamete } \\
{[\mathrm{mm}]}\end{array}$ & $\begin{array}{l}\text { Height } \\
{[\mathrm{mm}]}\end{array}$ & $\begin{array}{c}\text { Load } \\
{[\mathrm{g}]}\end{array}$ \\
\hline DA1 & 100 & 50 & 50 & DA1 & 100 & 50 & 25 & DB6 & 75 & 15 & 25 \\
\hline DA3 & 100 & 30 & 50 & DA2 & 100 & 50 & 25 & DC1 & 50 & 50 & 25 \\
\hline DA5 & 100 & 15 & 50 & DA4 & 100 & 30 & 25 & DC3 & 50 & 30 & 25 \\
\hline DB1 & 75 & 50 & 50 & DA6 & 100 & 15 & 25 & DC5 & 50 & 15 & 25 \\
\hline DB2 & 75 & 50 & 50 & DB1 & 75 & 50 & 25 & DC6 & 50 & 15 & 25 \\
\hline DB3 & 75 & 30 & 50 & DC1 & 50 & 50 & 25 & DB1 & 75 & 50 & 50 \\
\hline DB4 & 75 & 30 & 50 & DA3 & 100 & 30 & 50 & DB4 & 75 & 30 & 50 \\
\hline DB5 & 75 & 15 & 50 & DB2 & 75 & 50 & 50 & DB5 & 75 & 15 & 50 \\
\hline DB6 & 75 & 15 & 50 & DB3 & 75 & 30 & 50 & DA3 & 100 & 30 & 75 \\
\hline DC1 & 50 & 50 & 50 & DB4 & 75 & 30 & 50 & DA5 & 100 & 15 & 75 \\
\hline DC2 & 50 & 50 & 50 & DB6 & 75 & 15 & 50 & - & - & - & - \\
\hline DC3 & 50 & 30 & 50 & DC3 & 50 & 30 & 50 & - & - & - & - \\
\hline DC4 & 50 & 30 & 50 & DA5 & 100 & 15 & 75 & - & - & - & - \\
\hline DC5 & 50 & 15 & 50 & DB5 & 75 & 15 & 75 & - & - & - & - \\
\hline DC6 & 50 & 15 & 50 & DC2 & 50 & 50 & 75 & - & - & - & - \\
\hline DA4 & 100 & 30 & 75 & DC4 & 50 & 30 & 75 & - & - & - & - \\
\hline DA6 & 100 & 15 & 75 & DC5 & 50 & 15 & 75 & - & - & - & - \\
\hline- & - & - & - & DC6 & 50 & 15 & 75 & - & - & - & - \\
\hline
\end{tabular}

NOTE. - Nominal sample sizes are presented here. Actual diameters and heights sizes varied slightly and these were measured for each sample.

Analysis of results

\section{Repeatability}

Since repeatability standards have not been developed for the test yet, repeatability was studied based on the replicated results that were obtained for each testing condition/material combination. The conditions that need to be satisfied are same testing method, same laboratory, same operator, same equipment, short time span between tests, equivalent sample sizes and same material batch (ASTM E177). Out of the tests carried out, there were 10 pairs of identical samples that complied with these requirements. These were used to determine an appropriate $1 \mathrm{~s}$ index (one sigma limit) which allowed to establish the acceptable difference between the results measured (ASTM C670). The indentation at time $t=$ 40 seconds was used for comparison. Table 3 shows indentation results for the 10 pairs of identical samples.

In almost all cases the coefficient of variation CV between pairs of samples is lower or equal than 10\%. Only DB1-DB2, DB5-DB6 and DC3-DC4 pairs presented CV values higher than (21\%, 18\% and 13\% respectively). According to these results, it seemed reasonable to use a CV value equal to $10 \%$ to define the statistic $1 \mathrm{~s}$ for the purposes of this research. The $1 \mathrm{~s}$ value is calculated dividing the CV value obtained from pairs of samples by 2.8 (ASTM C670). Thus, the computed 
value of $1 \mathrm{~s}$ is equal to 0.04 . By using this criterion, it was possible to identify 4 abnormal data among the 45 tests performed. These outlier results were deleted from the analyses presented below.

Table 3. Indentation results and CV for pairs of identical samples. Source: Self-Elaboration.

\begin{tabular}{|c|c|c|c|c|c|c|c|c|c|c|}
\hline \multirow{2}{*}{$\frac{\text { Binder }}{\text { Load [g] }}$} & \multicolumn{6}{|c|}{ L1 (PG64-22) } & & & & \multirow{2}{*}{$\begin{array}{c}\text { L3 } \\
\text { (PG64-16 } \\
\text { reheated) } \\
25\end{array}$} \\
\hline & 50 & 50 & 50 & 50 & 50 & 50 & 25 & 50 & 75 & \\
\hline Test & DB1 & DB3 & DB5 & DC1 & DC3 & DC5 & DA1 & DB3 & DC5 & DC5 \\
\hline Sample & DB2 & DB4 & DB6 & DC2 & DC4 & DC6 & DA2 & DB4 & DC6 & DC6 \\
\hline $\mathrm{h}_{1}[\mathrm{~mm}]$ & 1.3 & 1.2 & 1.7 & 1.3 & 1.2 & 1.2 & 1.0 & 1.8 & 2.3 & 0.7 \\
\hline $\mathrm{h}_{2}[\mathrm{~mm}]$ & 1.8 & 1.4 & 1.3 & 1.2 & 1.4 & 1.3 & 0.9 & 1.7 & 2.1 & 0.7 \\
\hline CV & $21 \%$ & $10 \%$ & $18 \%$ & $3 \%$ & $13 \%$ & $6 \%$ & $7 \%$ & $1 \%$ & $9 \%$ & $3 \%$ \\
\hline
\end{tabular}

\section{Effect of sample height}

For the three different sample's height tested $(50,30$ and $15 \mathrm{~mm})$ it is expected that the lower the height, the lower the indentation. Figure 4(a) shows indentation results in binder L2 (PG64-16) for three sample heights, maintaining load (50 g) and radius of the sample $(35 \mathrm{~mm})$ constant. It may be verified that the lowest indentation occurs for the sample depth of $15 \mathrm{~mm}$ (i.e. minimum depth) and the highest indentation for the sample depth of $50 \mathrm{~mm}$ (i.e. maximum depth). Figure 4(b) also shows results after applying the correction factors for finite sample depth presented in section 2.2. The correction factor allows calculating the theoretical indentation in a sample of infinite height. It is verified that all indentations in the Figure 4(b) are similar after applying the correction factor, as expected. Coefficient of variation among indentations after 40 seconds decreased from 0.08 without applying correction factors, to 0.03 for corrected results. These trends, however, could not be verified in all cases (Filonzi, 2013).
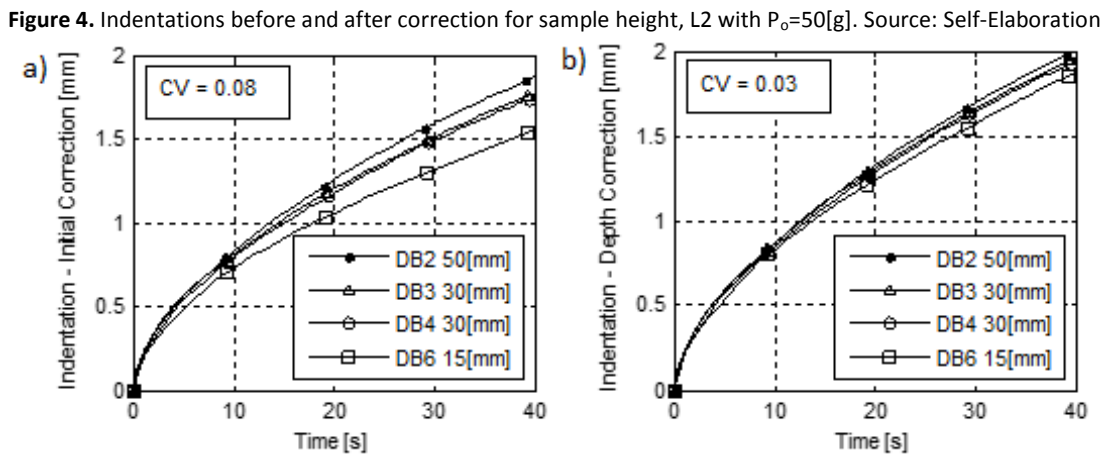

\section{Effect of sample radius}

For the three different sample's radius considered $(25,35$ and $50 \mathrm{~mm})$, it is expected that the lower the radius the lower the vertical displacement of indenter. Figure 5(a) shows indentation results of binder L2 (PG64-16) for three sample radiuses, maintaining the load ( $50 \mathrm{~g}$ ) and the height of the sample $(30 \mathrm{~mm}$ ) constant. The lowest indentation occurs for $R_{s}$ equal to $15 \mathrm{~mm}$ and the maximum indentation for $R_{s} 50 \mathrm{~mm}$. It is shown that for the selected sample's sizes and materials stiffness, the effect of the sample's radius is not as significant as its depth. Nevertheless, this effect may be significant for other test temperatures and smaller sample's radius, as shown by factors presented in Figure 2.

Figure 5(b) shows the indentation results corrected with the lateral correction factors presented in section 2.3. The corrected indentation represents the theoretical displacements in a sample of infinite diameter. It is shown that in this case, indentations become relatively closer together after applying the correction factors. Nevertheless, the effect is lower than the correction for finite depth, as it was previously noticed. The CV values among indentations after 40 seconds decreased from 0.03 , without applying correction factors, to 0.02 for the corrected results. It should be noted that given the test accuracy, the decrease in the CV value was not significant (Filonzi, 2013). 
Figure 5. Indentations before and after correction for sample radius, $\mathrm{L} 2$ with $\mathrm{Po}=50[\mathrm{~g}]$. Source: Self-Elaboration
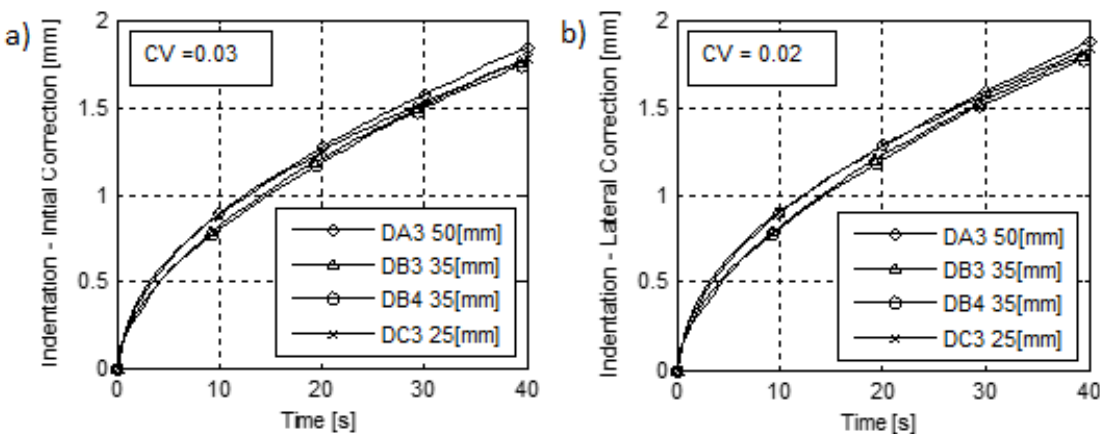

\section{Creep compliance}

Once indentation tests are corrected for sample size, creep compliance in shear is calculated through the analytical solution developed by Lee \& Radok (1960). This solution assumes a linear viscoelastic behavior of the tested binder and a semi-infinite sample. The assumption is valid after application of height and lateral correction factors. Figure 6 shows the creep compliance results for binder L2 (PG64-16).

\section{Effect of indentation load on creep compliance}

The creep compliance functions calculated are valid in the linear viscoelastic range response of asphalt binders. This assumption is not valid if the results depend on the load applied. Figure 6 shows that creep compliance results obtained, with a load of $25 \mathrm{~g}$, differ significantly from those obtained with loads of 50, and $75 \mathrm{~g}$. Similar results were obtained by Zofka \& Nener-Plante (2011), they reported discrepancies between different indentation load levels.

To verify if creep compliance results obtained from different indentation loads belong or not to the same sample an analysis of variance ANOVA was performed. Fisher's least significance difference (LSD) test (Montgomery \& Runger, 2010), was applied with a 95\% confidence. Three analysis groups were defined for each asphalt binder, according to the indentation load level $(25,50$, and $75 \mathrm{~g})$. The analysis results indicated that there are significant differences for all pairs of indentation load levels, except for the load pair of 50, and $75 \mathrm{~g}$. This was verified for each of the three binders analyzed. In other words, it may be assumed that for indentation loads of 50, and $75 \mathrm{~g}$ approximately the same creep compliance occurs, regardless the load applied. When $25 \mathrm{~g}$ of load are applied, creep compliance obtained showed significant differences with the other two load levels.

The effect is not related to a non-linear response by the asphalt binder. The asphalt binder's response is linear viscoelastic at low stress (strain) levels and non-linear at high stress levels (Delgadillo, Cho \& Bahia, 2006; Delgadillo \& Bahia, 2010; Delgadillo, Bahia \& Lakes, 2012). Consequently, differences must be due to other reasons. One cause could be that for very low load levels the assumption that friction between surfaces is negligible as compared to the load applied is not valid. Determining the actual causes might require further studies with models that include friction and adhesion (Johnson, 1985).

For the purposes of the current research, the results obtained with $25 \mathrm{~g}$ of load were disregarded. In the next sections only the 50 , and $75 \mathrm{~g}$ indentation results will be used, for which the response was assumed to be linear, independent from the indentation load level.

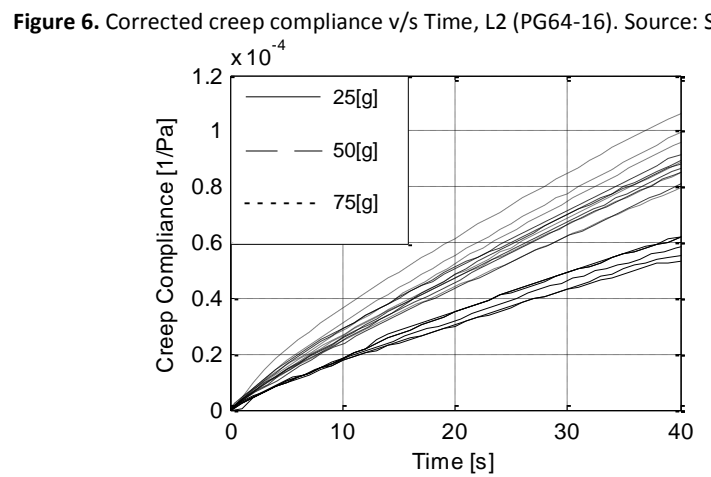




\section{Comparison with creep compliances obtained with a DSR}

Creep compliance in shear for the three asphalt binders was also determined using a Dynamic Shear Rheometer DSR (Anton Paar Physica - Model MCR 301). Binder samples for DSR were subject to the same heating procedures as samples for indentation, but in closed containers. Parallel plates' geometry was used with a 25 millimeters diameter and a constant creep stress of $100 \mathrm{~Pa}$. Previous studies indicate a linear response by asphalt binders in this stress range (Delgadillo et al., 2006). Results obtained through both testing methods were compared. Figure 7(a) shows the results for binder L1 (PG64-22). The two continuous curves represent creep compliances in shear obtained with DSR for the maximum and minimum temperature ranges recorded during binder's indentation test $\left(21.4\right.$ and $\left.20.6^{\circ} \mathrm{C}\right)$. These two curves define the creep compliance range expected from the indentation tests for this asphalt binder.

Segmented lines represent creep compliances obtained from the different indentation tests on the same binder. The results do not coincide with those measured with DSR, and indentation results represent a more rigid material than the DSR results. The same trend was verified for the other two binders (Filonzi, 2013). These results agree with previous research. Zofka \& Nener-Plante (2011) reported significant differences between indentation at low temperatures and Bending Beam Rheometer results. Ossa et al. (2005) also obtained a smaller creep compliance (more rigid) when indentation was used.
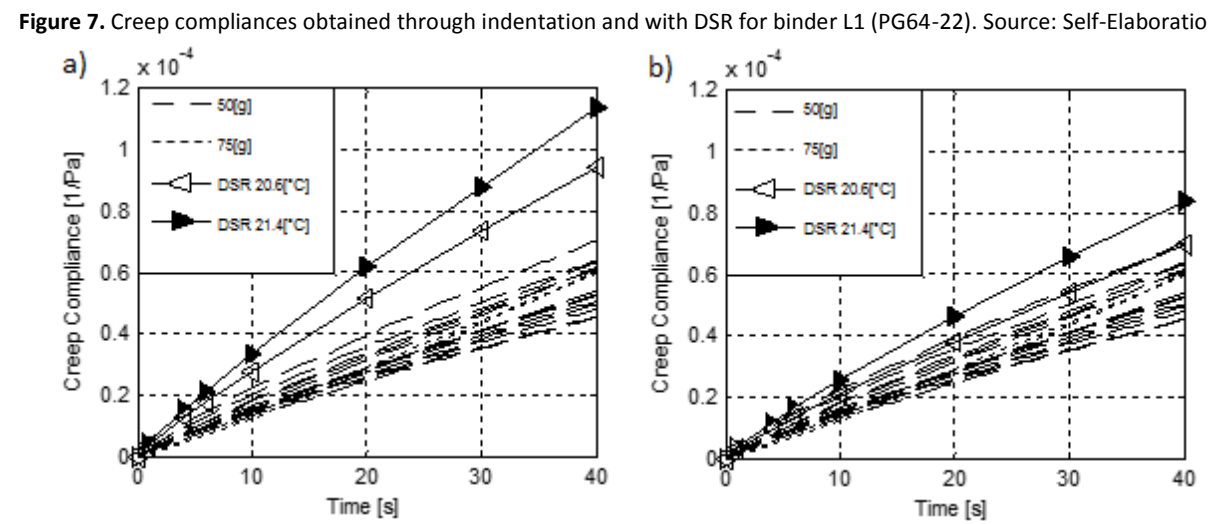

One of the reasons for this difference could be the excessive aging induced on the surface of the samples for indentation. Preparation of samples for indention requires the formation of a perfectly flat indenting surface. In order to achieve this, it is necessary to heat test containers in high-temperature ovens so that material liquefies, releases all air bubbles and becomes a flat surface when it cools down. Such process originates aging and hardening of the surface to indent, which may be the cause of lower creep compliances. The rest of the sample to be indented was not directly exposed to oxygen, which probably results into a sample with a significant stiffness variation through height, thus making the sample heterogeneous and difficult to characterize.

Asphalt binder samples were stored for approximately six months after the indentation tests were carried out. To check if the more aged samples would have creep compliances more similar to the ones obtained by indentation, the aged samples were tested with DSR. The DSR creep compliances for the aged samples are presented in Figure 7(b) and compared with the original creep compliances from indentation for binder L1 (PG64-22). The aged DSR results are closer to those obtained through indentation. This could confirm the effect of the aging on the surface to be indented. The same behavior was verified for the other two binders (Filonzi, 2013).

\section{Conclusions and recommendations}

In this study, a modified penetrometer is used to perform linear viscoelastic characterization of asphalt binders. Although the new test method has shown promising results, a significant improvement in testing equipment is needed. A conventional penetrometer does not allow for a precise and timely application of the load at the beginning of the test. It is possible to overcome such limitations by incorporating a greater sophistication level to the equipment. Care must be taken so that modifications do not imply excessive costs, which would defeat the whole purpose of a low-cost characterization. Furthermore, characterization at different temperatures would require a temperature control chamber, which could also increase significantly the cost of the equipment. 
Available closed form solutions for indentation assume that the indented material is semi-infinite. In order to satisfy such assumption, for some materials and testing conditions the sample sizes required may become too large for practical purposes. Correction factors for lateral and bottom boundary conditions where developed in this work. These factors allow for the use of smaller and easier to handle sample sizes.

In the analyses carried out it was assumed that the friction between surfaces was negligible. The difference between creep compliances obtained with the lower load ( $25 \mathrm{~g}$ ) as compared to that calculated with higher loads (50, and $75 \mathrm{~g}$ ) indicates the possibility that such assumption could not be valid for lower loads. It is recommended to study the effect of friction and adhesion in future developments of this test. The correction factors for boundary conditions that were developed in this paper may significantly facilitate that task. Such factors allow using spherical indenters with large diameters as compared to the sample size. Large diameters ensure a greater perpendicularity between surfaces during indentation, thus reducing friction effect.

Creep compliance results obtained through indentation were in all cases lower than those measured with the DSR. This would indicate that indented material is more rigid than the material tested with the DSR. A possible cause for this discrepancy may be the neglected friction between the surfaces in contact. Another possible cause is the superficial aging of the asphalt binder during preparation of the samples for indentation. A sample with properties varying through the height is more difficult to characterize.

Acknowledgements

This work was partially sponsored by the Comisión Nacional de Investigación Científica y Tecnológica de Chile CONICYT, under FONDECYT program, grant 11110255. Special thanks to the staff of the Laboratorio de Ensaye de Materiales $y$ Control de Obras LEMCO at Universidad Técnica Federico Santa María - Chile.

References

AASHTO, MP. (1998). 19 Standard specification for performance graded asphalt binder. American Association of State Highway and Transportation Officials.

AASHTO, T. (2008). 313 Standard Method of Test for Determining the Flexural Creep Stiffness of Asphalt Binder Using the Bending Beam Rheometer (BBR). American Association of State Highway and Transportation Officials.

AASHTO, T. (2012). 315 Standard Method of Test for Determining the Rheological Properties of Asphalt Binder Using a Dynamic Shear Rheometer (DSR). American Association of State Highway and Transportation Officials.

Anderson, D. A., Christensen, D. W., Bahia, H. U., Dongre, R., Sharma, M. G., Antle, C. E., \& Button, J. (1994). Binder characterization and evaluation, volume 3: Physical characterization. Strategic Highway Research Program, National Research Council, Report No. SHRP-A-369.

ASTM, C. (1999). C670, Standard Practice for Preparing Precision and Bias Statements for Test Methods for Construction Materials. USA: Annual Book of ASTM Standards.

ASTM, D. (2006). D5, Standard Test Method for Penetration of Bituminous Materials. USA: Annual Book of ASTM Standards.

ASTM, D. (2009). D36. Standard Test Method for Softening Point of Bitumen (Ring-and-Ball Apparatus). USA: Annual Book of ASTM Standards.

ASTM, D. (2007). D113.Standard Test Method for Ductility of Bituminous Materials. USA: Annual Book of ASTM Standards.

ASTM, E. (2008). E117. Standard Practice for Use of the Terms Precision and Bias in ASTM Test Methods. USA: Annual Book of ASTM Standards.

Bahia, H., Meruva, A., \& Velasquez, R. (2011). Modification of the Penetration Test to Measure Rheological Properties of Bitumen [Special issue]. Asfaltos y Pavimentos, 21(1), 13-27.

Benedetto, H. D., Delaporte, B., \& Sauzéat, C. (2007). Three-dimensional linear behavior of bituminous materials: experiments and modeling. International Journal of Geomechanics, 7(2), 149-157.

Bowden, F. P., \& Tabor, D. (2001). The friction and lubrication of solids (Vol. 1). Cambridge, United Kingdom: Cambridge University Press.

Cao, Y. P., \& Lu, J. (2004). A new method to extract the plastic properties of metal materials from an instrumented spherical indentation loading curve. Acta Materialia, 52(13), 4023-4032.

Delgadillo, R., \& Bahia, H. U. (2010). The relationship between nonlinearity of asphalt binders and asphalt mixture permanent deformation. Road Materials and Pavement Design, 11(3), 653-680.

Delgadillo, R., Cho, D., \& Bahia, H. (2006). Part 1: bituminous materials: nonlinearity of repeated creep and recovery binder test and relationship with mixture permanent deformation. Transportation Research Record: Journal of the Transportation Research Board, (1962), 3-11. 
Filonzi, A. (2013). Modelación de deformaciones por ensayo de indentación en ligantes asfálticos. (Master thesis). Universidad Técnica Federico Santa María, Valparaíso, Chile.

Filonzi, A., \& Delgadillo, R. (2017). Sample size correction factors for indentation on asphalt bitumens. Construction and Building Materials, 154, 877883 .

García, A., Bueno, M., Norambuena-Contreras, J., \& Partl, M. N. (2013). Induction healing of dense asphalt concrete. Construction and Building Materials, 49, 1-7.

Hajj, E., Souliman, M., Alavi, M., \& Loría Salazar, L. (2013). Influence of hydrogreen bioasphalt on viscoelastic properties of reclaimed asphalt mixtures. Transportation Research Record: Journal of the Transportation Research Board, (2371), 13-22.

Han, S. M., Saha, R., \& Nix, W. D. (2006). Determining hardness of thin films in elastically mismatched film-on-substrate systems using nanoindentation. Acta Materialia, 54(6), 1571-1581.

Hertz, H. (1882). Über die Berührung fester elastischer Körper. Journal für die Reine und Angewandte Mathematik, 92, $156-171$.

Hunter, S. C. (1960). The Hertz problem for a rigid spherical indenter and a viscoelastic half-space. Journal of the Mechanics and Physics of Solids, 8(4), 219-234.

Johnson, K. L. (1985). Contact mechanics (Vol. 1). Cambridge, United Kingdom: Cambridge University Press.

Johnson, K. L., Kendall, K., \& Roberts, A. D. (1971, September). Surface energy and the contact of elastic solids. In Proceedings of the Royal Society of London A: Mathematical, Physical and Engineering Sciences, 324(1558), 301-313). The Royal Society.

Lee, E. H. (1955). Stress analysis in visco-elastic bodies. Quarterly of Applied Mathematics, 13(2), 183-190.

Lee, E. H., \& Radok, J. R. M. (1960). The contact problem for viscoelastic bodies. Journal of Applied Mechanics, $27(3)$, 438-444.

Li, H., \& Vlassak, J. J. (2009). Determining the elastic modulus and hardness of an ultra-thin film on a substrate using nanoindentation. Journal of Materials Research, 24(3), 1114-1126.

Marín Uribe, C. R., \& Thenoux Zeballos, G. A. (2014). Validation of the polygon of voids tool for asphalt mixtures with RAP. Revista de la Construcción, 13(1), $56-63$

Montgomery, D. C., \& Runger, G. C. (2010). Applied statistics and probability for engineers. John Wiley \& Sons.

MOP (2003). Volumen 8: Especificaciones y método de muestreo. Ensayo y control. Ministerio de Obras Públicas y Urbanismo. Santiago de Chile, Chile.

Ossa, E. A., Deshpande, V. S., \& Cebon, D. (2005). Spherical indentation behaviour of bitumen. Acta Materialia, 53(11), 3103-3113.

Read, J., \& Whiteoak, D. (2003). The shell bitumen handbook. Thomas Telford.

Roberts, F. L., Kandhal, P. S., Brown, E. R., Lee, D. Y., \& Kennedy, T. W. (1991). Hot mix asphalt materials, mixture design and construction. NAPA Research and Education Foundation, Lanham, MD.

Sharpe, W. N. (Ed.). (2008). Springer handbook of experimental solid mechanics. Springer Science \& Business Media.

Sneddon, I. N. (1965). The relation between load and penetration in the axisymmetric Boussinesq problem for a punch of arbitrary profile International Journal of Engineering Science, 3(1), 47-57.

Standard, E.N. (1999). 12593. Bitumen and bituminous binders - Determination of the Fraass breaking point. Brussels: European Committee for Standardization.

Valdés Vidal, G., Miró Recasens, R., \& Martínez Reguero, A. (2015). Assessment of the adhesive capacity of asphalt binders in the aggregate-binder bonds by means of new methodology. Revista de la Construcción, 14(1), 69-76.

Yang, F., \& Li, J. C. M. (2008). Micro and nano mechanical testing of materials and devices. New York: Springer

Western Research Institute (WRI), (2010). Quarterly technical progress report October 31 - December 31. (Subtask E1b-2: Feasibility of Determining Rheological and Fracture Properties of Thin Films of Asphalt Binders and Mastics using Simple Indentation Tests) Federal Highway Administration. Contract Number (DTFH61-07-H-00009). Retrieved from Asphalt Research Consortium Website: http://www.arc.unr.edu/Reports/QuarterlyReport_Oct-Dec_09.pdf

Zofka, A., \& Nener-Plante, D. (2011). Determination of asphalt binder creep compliance using depth-sensing indentation. Experimental mechanics, $51(8), 1365-1377$ 